\title{
Life tables for sunn pest, Eurygaster integriceps (Heteroptera: Scutelleridae) in northern Iran
}

\author{
S. Iranipour ${ }^{1}$, A. Kharrazi Pakdel ${ }^{2}$, G. Radjabi ${ }^{3}$ \\ and J.P. Michaud ${ }^{4 *}$
}

${ }^{1}$ Department of Plant Protection, Faculty of Agriculture, University of Tabriz, Tabriz, 51666-14888 Iran: ${ }^{2}$ Department of Plant Protection, Faculty of Agriculture, University of Tehran, Karaj, Iran: ${ }^{3}$ Plant Pests and Diseases

Research Institute, PO Box 1454-19395 Tehran, Iran: ${ }^{4}$ Kansas State University, Agricultural Research Center-Hays, 1232 240th Ave, Hays, Kansas 67601, USA

\begin{abstract}
Life table studies of sunn pest were carried out in Varamin, Iran, from 19982001 in order to determine stage-specific mortalities and the impact of specific natural enemies on population dynamics. Populations were sampled 2-3 times weekly in agricultural fields during the growing season and monthly during the period of dormancy at resting sites in nearby mountains some $30 \mathrm{~km}$ away from cereal fields. Adults spend a period of 9-10 months in diapause and suffered overcompensatory, density-dependent mortality during this period. Variation in adult overwintering survival was inferred to be largely a function of the physiological condition of bugs that is reduced in a density-dependent manner by intraspecific competition for food among newly molted adults prior to migration to resting sites. Adult mortality emerged as the primary factor in key factor analysis, contributing $73 \%$ of the total variance in mortality. Other important factors were egg parasitism by Trissolcus vassilievi Mayr and adult parasitism by several species of Tachinidae. Although $T$. vassilievi made only a minor contribution to overall variance in total mortality, it had a significant effect on the number of newly molted adults, the life stage that is most damaging to cereal crops. The equilibrium level of the pest population in wheat fields was inferred to be $c a .72 .6$ adults $\mathrm{m}^{-2}$, a number that substantially exceeds the economic threshold that ranges from $3-5$ adults $\mathrm{m}^{-2}$.
\end{abstract}

Keywords: life table, parasitism, population dynamics, Tachinidae, Trissolcus spp, wheat

(Accepted 28 February 2010)

\section{Introduction}

Sunn pest, Eurygaster integriceps Puton, is the most economically important pest of cereals in Iran and throughout the Middle East (Radjabi, 2000). Despite a long history of

*Author for correspondence losses from sunn pest in Iran, there does not yet exist an Fax: 785-623-4369 integrated management strategy for its control. A compre-

E-mail: jpmi@ksu.edu hensive understanding of its life history and the forces 
driving population fluctuations is sorely needed. Since Afshar's (1933) publication on E. integriceps, there have been many other studies of its life history and natural enemies (e.g. Alexandrev, 1947a,b; Davatchi, 1954; Safavi, 1973; Salavatian, 1991), the most detailed of which was provided by Radjabi (2000).

Although invariably univoltine, the life cycle of E. integriceps varies to some degree with geographical location. Adults spend most of the year in obligatory diapause prior to reproduction. In colder regions, diapausing bugs remain in the vicinity of cereal fields; whereas, in more moderate climates and dry regions, they may migrate a considerable distance to resting sites. In Varamin County, adults leave lower elevation fields $(\approx 1000 \mathrm{~m}$ ASL) in summer (late June) and fly as far as $30 \mathrm{~km}$ into nearby mountains $(\approx 2300 \mathrm{~m}$ ASL). Here, adults colonize various plant species (predominantly Artemisia spp.) but remain largely inactive. They move locally when temperatures are sufficiently high and may feed on plant juices while the plants remain alive, but they do not reproduce. After emerging from dormancy, the surviving adults return to agricultural fields and, after feeding for a short time, mate and begin laying egg masses that range in size from 2-30 eggs. Oviposition continues for about a month, so there is considerable overlap in the presence of various nymphal stages within a season. Completion of the five nymphal instars requires about a month and a half, whereupon newly molted adults of next generation appear. These feed for a week or two in order to accumulate fat reserves and, in so doing, produce the majority of crop damage, both quantitative (yield loss by weight) and qualitative (grain damage as a result of injected salivary secretions). Grain with feeding damage to more than $2 \%$ of kernels is rejected and cannot be sold (Radjabi, 2000). After this initial feeding period, the adults migrate to their resting sites where they first aestivate and then hibernate over a period that spans 9-10 months, before finally migrating back to cultivated fields.

Many publications have examined factors affecting the abundance of sunn pest in the Middle East (Vojdani, 1961; Martin et al., 1969; Safavi, 1973; Javahery, 1978; Farid, 1984; Marashi, 1988; Ghadiri \& Heydari, 1989; Khalaf \& Shadai, 1990; Salavatian, 1991; Mardoukhi \& Heydari, 1993; Radjabi, 1994, 1995a,b, 2000). However, only a few studies (Radjabi, 2000, 2007; Tafaghodinia, 1994) have formally addressed population dynamics. Tafaghodinia (1994) constructed life tables of the pest for two generations. Due to lack of data for the diapause period, the life table for the second year was incomplete. The author concluded that the earliest life stages (eggs and first instar nymphs) suffered the bulk of mortality and that survivorship curves were of type IV (sensu Slobodkin, 1962). Radjabi (2007) recently published a fiveyear study that spanned periods before and after the 1962 outbreak in Isfahan. He concluded that outbreaks occurred in cycles with a period of 5-8 years (seven years on average) without pesticide intervention, driven largely by intraspecific competition among adults for food. However, other studies in Russia (Kartavtsev, 1974; Doroninia \& Makarova, 1976; Volodichev, 1991, 1996; Gordeev, 1998; Tikhomolov \& Borisov, 1998) Romania (Banita et al., 1994) and Yugoslavia (Udovitsa, 1998) have attributed population fluctuations of E.integriceps and related species to effects of natural enemies and weather conditions. The increasing use of broad spectrum insecticides against this pest may also have changed its natural population dynamics in some areas.
Here, we investigated the population dynamics of sunn pest in the cereal-growing region of Varamin in northern Iran using a life table approach.

The purpose of this study was to obtain information on the biology and natural enemies of sunn pest in order to generate life table analyses. This approach requires sampling all life stages of the pest across sequential years and/or different locations to obtain 'stage frequency data' (Manly, 1990; Bellows et al., 1992; Dent, 1997; Young \& Young, 1998; Southwood \& Henderson, 2000). Many analytical methods for such data are available in the literature (reviewed by Manly (1990) and Dent (1997). The difference in abundance between two successive life stages produces an estimate of stage-specific mortality. Wherever possible, it is desirable to separate the various components of stage-specific mortality, such as parasitism, predation, disease, etc. For this purpose, the marginal attack rate (Elkinton et al., 1992; Carey, 1993) is typically used to provide an estimate of the intensity of a mortality factor acting in the absence of others. When a series of life tables are available, both key factor analysis and density dependence analysis can be performed. Key factor analysis identifies the principle mortality factors driving changes in abundance. Mechanisms of population regulation are commonly identified using linear regression. Single factor analysis was the earliest method applied (Morris 1957, 1959) and was followed by Varley \& Gradwell's (1960) graphical analysis and Smith's (1973) co-variance analysis. Other methods include those of Podoler \& Rogers (1975), Manly(1977, 1979, 1990), Sibly \& Smith (1998) and Yamamura (1999). For the present study, we selected the methods of Smith (1973) and Podoler \& Rogers (1975) that have both been widely used, and those of Manly $(1977,1979)$ that employ a different conceptual approach.

\section{Materials and methods \\ Sampling locations}

Populations of E. integriceps were sampled from 1998 to 2001 in Varamin County, in the vicinity of Tehran. Each year, a wheat field was sampled in Jalilabad $\left(35^{\circ}, 21^{\prime} \mathrm{N}\right.$ latitude and $51^{\circ}, 47^{\prime} \mathrm{E}$ longitude). In 1999, an additional barley field was sampled in Jalilabad and, in 2000, an additional wheat field in Sharifabad, located $8 \mathrm{~km}$ to the north. Sampling was carried out from April to June. Economic damage by sunn pest is predictable in this region, such that wheat fields are conventionally sprayed with insecticides from fixed-wing aircraft. In order to minimize the impact of these insecticide treatments on our data, we selected plots under power lines that would not receive direct application. Crop rotation and fallow periods necessitated the selection of new plots each year.

Diapausing bugs were sampled on the northern mountain of Qara-aghaj between elevations of 1800 and $2300 \mathrm{~m}$ ASL, $18 \mathrm{~km}$ distant from the nearest cultivated fields beside the Tehran - Khorasan highway, and $30 \mathrm{~km}$ distant from the study fields.

\section{Sampling methods}

Bugs were sampled in cultivated fields in a systematic pattern using a series of $0.25 \mathrm{~m}^{2}$ quadrats $(n=25)$ spaced ten paces apart. Quadrats were sampled by visually counting all life stages of the pest. In order to obtain an estimate of egg 
mortality, all egg masses were transported to the laboratory and held in at ambient room temperature $\left(\mathrm{ca} .22^{\circ} \mathrm{C}\right)$ until emergence of either nymphs or parasitoids.

In order to evaluate adult parasitism by tachinid flies, between 50-100 adults were collected weekly and dissected to determine if they contained parasitoid larvae. These samples were taken from fields contiguous to the study area - no bugs were removed from study fields. Since larval parasitoids could not be identified to species, only a value for total adult parasitism was obtained.

Diapausing adults were sampled at resting sites monthly from July to March by randomly selecting 30 Artemisia spp. plants on each sampling date. All bugs on each plant were counted and then stored in rectangular plastic containers $(20 \times 14 \times 6 \mathrm{~cm})$ for subsequent dissection.

\section{Life stage calculations}

When temperatures in spring reach $13.5-14.3^{\circ} \mathrm{C}$, adult bugs begin to leave hibernation sites to return to cereal fields for reproduction (Radjabi, 2000). Southwood \& Jepson's (1962) graphical method was used to estimate the number of bugs entering each immature stage. This method involves dividing the area under the curve of stage frequency data by the mean duration of the life stage in degree-days. Thermal constants for the development of immature stages were assumed to be 38.83, 25.55, 55.10, 43.93, 45.53 and 66.32 degree-days for eggs and the five nymphal instars, respectively, above a threshold of $18.85^{\circ} \mathrm{C}$ (Iranipour et al., 2003). Daily temperatures above threshold were estimated using the triangle method of Bernal \& Gonzalez (1993), which assumes a linear change between maximum and minimum temperatures and a 12-h interval between them. Weather data was obtained from the Mamazan weather station at the Higher Education Institute of Aboureyhan, Faculty of Agriculture, University of Tehran, situated $<20 \mathrm{~km}$ from the study fields. It was assumed that temperature differences between fields and the weather station would be negligible or at least follow similar trajectories. The number of bugs entering the adult stage was estimated as the cumulative number of adults plus all previous stages at the peak of the adult molt, since after this point numbers decline due to emigration to aestivation sites. In the case of parental females, we assumed a stage duration of ten days, a somewhat conservative estimate.

Life tables were initiated by assuming a hypothetical stage, the 'potential egg'. The number of potential eggs was calculated as:

$$
\mathrm{E}_{\mathrm{p}}=209.36 \times \mathrm{F}(1-\mathrm{P})
$$

where 209.36 is the maximum female fecundity recorded in the laboratory on Mahdavi wheat kernels (Iranipour et al., 2003), $\mathrm{F}$ is the number of parental females at the beginning of field colonization, and $\mathrm{P}$ is the rate of female parasitism. The number of first instar nymphs was calculated by subtracting egg mortality from the initial number of actual eggs. For numbers of subsequent nymphs, counts within quadrate were used; but, unfortunately, these counts were subject to irregular increases, rather than decreases, with age, apparently because early instars are difficult to observe and frequently overlooked. Thus, we had greater confidence in our estimates of egg and adult numbers. Eggs can be counted reliably and fragments of chorion remain adhering to the plant following predation events. Thus, we avoided the assumption of Southwood \& Jepson (1962) that all the mortality occurred at the end of the egg stage, and we were able to use total eggs in calculating the area under curve, rather than only surviving eggs. Adults are large and more easily observed in situ than nymphal stages. Thus, overall mortality from 1st instar nymph to adult was processed as a single mortality factor. All values were expressed per square meter of habitat. The following mortality factors ( $k$-values) were identified:

$\mathrm{k}_{0}$ : difference between potential and actual eggs

$\mathrm{k}_{\mathrm{E}}$ : egg mortality, divided into seven submortalities as follows:

$\mathrm{k}_{\mathrm{E} 1}$ : overall predation

$\mathrm{k}_{\mathrm{E} 2}-\mathrm{k}_{\mathrm{E} 6}$ : parasitism due to five species of egg parasitoid: Ooencyrtus telenomicida Vassiljev, Trissolcus grandis (Thompson), T. vassilievi (Mayr), T. semistriatus (Nees), and T. basalis (Wollaston) $\mathrm{k}_{\mathrm{E} 7}$ : infertility

Note 1. Marginal attack rates were calculated according to the method of Elkinton et al. (1992) assuming that (i) predators do not discriminate against parasitized eggs, (ii) O. telenomicida parasitizes host eggs at the same rate it hyperparasitizes Trissolcus spp., (iii) Trissolcus species all have similar probability of emergence from multiplyparasitized eggs and (iv) parasitoids do not distinguish fertile eggs from infertile ones.

$\mathrm{k}_{\mathrm{N}}$ : nymph mortality, a single factor estimating mortality across all five nymphal stages.

$\mathrm{k}_{\mathrm{A}}$ : adult mortality prior to reproduction, estimated as the difference between the number of pre-reproductive adults observed in the current year and the number of parental adults observed the following year. This was divided into two submortalities as follows:

$\mathrm{k}_{\mathrm{A} 1}$ : mortality at resting sites (during both aestivation and hibernation periods), measured as the slope of the negative linear regression equation that best estimated the decline in numbers over time on a natural log scale. $\mathrm{k}_{\mathrm{A} 2}$ : residual mortality, mortality occurring during the premigratory feeding period and both migration periods, calculated as $\mathrm{k}_{\mathrm{A} 2}=\mathrm{k}_{\mathrm{A}}-\mathrm{k}_{\mathrm{A} 1}$

Note 2. $\mathrm{k}_{\mathrm{A} 2}$ contains an inherent source of error in that the parental bugs in a field are not the same adults generated in that field the previous year.

Note 3. Although tachinid flies (presumably the second generation) attack pre-reproductive adults, this was not processed as a distinct mortality factor in the key factor analysis because it is delayed in effect and contributes to mortality during the remainder of the stage.

$\mathrm{k}_{\mathrm{P}}$ : parental mortality was divided into two submortalities:

$\mathrm{k}_{\mathrm{P} 1}$ : sex ratio. Because of gender-specific mortality rates, the sex ratio of reproductive bugs was always more than 0.5 . Since males produce no progeny, the number of males was subtracted from the total number of adult bugs observed to yield the number of parental females.

$\mathrm{k}_{\mathrm{P} 2}$ : female parasitism by tachinids. Parasitism was estimated separately for the two sexes; but, because males were excluded in the previous step, only female parasitism included in life tables. Both sexes become 
Table 1. Observed sources of mortality (in percent) for Eurygaster integriceps eggs in various cereal fields sampled in northern Iran over three years.

\begin{tabular}{|c|c|c|c|c|c|}
\hline \multirow[t]{2}{*}{ Factor } & \multicolumn{3}{|c|}{ Jalilabad wheat } & \multirow{2}{*}{$\frac{\text { Jalilabad barley }}{1999}$} & \multirow{2}{*}{$\frac{\text { Sharifabad wheat }}{2000}$} \\
\hline & 1998 & 1999 & 2000 & & \\
\hline Infertility & 9.17 & 5.64 & 7.72 & 2.44 & 4.54 \\
\hline Ooencyrtus telenomicida & 0.00 & 1.28 & 0.00 & 0.33 & 0.79 \\
\hline Trissolcus basalis & 0.00 & 0.00 & 1.7 & 0.36 & 0.00 \\
\hline Trissolcus grandis & 26.72 & 19.39 & 17.19 & 18.93 & 20.31 \\
\hline Trissolcus semistratus & 0.00 & 1.47 & 0.00 & 0.82 & 0.00 \\
\hline Total mortality & 37.94 & 46.43 & 41.06 & 47.93 & 76.22 \\
\hline
\end{tabular}

sterile when parasitized. After subtracting $\mathrm{k}_{\mathrm{P} 1}$ and $\mathrm{k}_{\mathrm{P} 2}$, we are left with the number of females that survive to reproduce and contribute to the next generation.

\section{Key factor analysis}

For sake of comparison, three different methods were used: (i) the regression method of Podoler \& Rogers (1975); (ii) the covariance and correlation analysis of Smith (1973); and (ii) Manly's (1977, 1979, 1990) method for deriving density-dependent mortalities. All methods were applied once for whole stages and again for submortalities. The generation starting point varied among analyses. For example, in the Podoler-Rogers method, generations began with parental adults rather than eggs. Since both the starting point and the sequence of mortality factors strongly affect key factors in the Manly method (each density dependent factor decreases the intensity of a subsequent factor), generations were considered to begin with potential eggs and terminate with ovipositing females. This resulted in estimates of the relative impact of each factor on changes in the number of ovipositing females. We repeated this analysis in a sequence that terminated in newly molted adults in order to identify the factor with greatest impact on this most injurious stage.

Note 4: Because all mortalities must be processed in series with Manly's method, simultaneous sources of mortality were considered as a single mortality factor. Because of the sizable contribution of both T. grandis and T. vassilievi to total parasitism, the analysis was repeated substituting each in turn for total egg parasitism.

Note 5: We processed $\mathrm{k}_{\mathrm{A}}$ as a single mortality factor in the Manly analysis because of our inability to resolve its components.

Density-dependent relationships were determined by linear regression. Simultaneous factors were plotted against the initial numbers of the same life stage (minus all previous serial submortalities, if present).

\section{Results \\ Egg mortality}

The mortality of E. integriceps eggs attributable to various causes is shown in table 1. Egg infertility approached $10 \%$ in one year, but predators and the facultative hyperparasitoid O. telenomicida caused negligible mortality $(<3 \%)$. However, parasitism by two Trissolcus spp. (=percent mortality in table 1) was substantial; parasitism by T. vassilievi was somewhat variable, whereas $T$. grandis had a more consistent impact.

\section{Sex ratio}

Males and females were equally abundant among newly molted adults, but the sex ratio in parental bugs was biased in favor of females, apparently due to a lower survival rate among pre-reproductive males. Sex ratios for the five cohorts at onset of reproduction were estimated to be 70.6, 76.1, 78.4, 68.8 and $81.7 \%$ for Jalilabad wheat fields in 1998, 1999, 2000, Jalilabad barley in 1999 and Sharifabad wheat in 2000, respectively.

\section{Adult parasitism}

As previously noted, at least two generations of flies attack a single generation of E. integriceps, so that both parental bugs and newly-molted adults are attacked in cultivated fields (table 2). There was evidence of host resistance in that some fly larvae were encountered dead and melanized; these were tallied separately as 'encapsulated'. Newly molted adult bugs experienced only slight mortality and appeared to have stronger resistance in the form of higher rates of encapsulation, whereas parasitism of reproductive females early in the season had greater population impact. Among parental adult bugs, tachinids expressed a significant preference for female hosts $(t=2.503$, $\mathrm{df}=10, P=0.05)$. Since these flies are all solitary parasitoids, superparasitized bugs (which presumably included some multiparasitized individuals) contained only a single surviving larva. There was a higher rate of superparasitism in the parental cohort than in the subsequent generation, and more females were superparasitized than males. Superparasitism tended to be higher in fields with higher adult bug densities and appeared to be a significant source of density-dependent mortality in the fly population(s), with some hosts yielding as many as seven fly maggots. The number of bugs containing two larvae was greater than the number containing three, which was in turn greater than the number containing four, etc., as would be expected if superparasitism 
Table 2. Summary of data for E. integriceps percent parasitism by tachinid flies in various years and study locations, and percentage of parasitized hosts that encapsulated fly larvae.

\begin{tabular}{|c|c|c|c|c|c|c|c|}
\hline & & 1998 & 1999 & 2000 & 2001 & $\begin{array}{c}1999 \\
\text { Barley }\end{array}$ & $\begin{array}{c}2000 \\
\text { Sharifabad }\end{array}$ \\
\hline \multirow{4}{*}{ 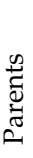 } & Females & 23.2 & 25.4 & 36.1 & 38.3 & 24.6 & 58.1 \\
\hline & Males & 16.2 & 15.0 & 16.0 & 21.3 & 29.0 & 34.1 \\
\hline & Superparasitized & 4.1 & 5.1 & 10.2 & 39.7 & 6.2 & 34.1 \\
\hline & Encapsulated & 1.1 & 0.0 & 1.2 & 0.9 & 0.0 & 1.1 \\
\hline \multirow{3}{*}{ 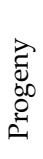 } & Females & 12.8 & & & & & \\
\hline & Superparasitized & 13.8 & 0.0 & 0.0 & & & \\
\hline & Encapsulated & 8.6 & 7.0 & 0.0 & & & \\
\hline
\end{tabular}

occurs simply because of a failure to discriminate previously parasitized hosts.

\section{Other adult mortality factors}

Adult bugs suffer heavy mortality during diapauses, and our observations indicate that the majority occurs in October and November. Pre-reproductive adult mortality can be divided into two fractions: (i) mortality during hibernation and aestivation at resting sites, and (ii) mortality occurring prior to emigration from cultivated fields and during the migrations to and from resting sites. These two were separated in order to segregate mortality associated with migration from the key factor, overwintering mortality (see key factor analysis below).

Mortality during the entire dormant period was estimated using a linear regression model; ln(no. bugs) was plotted against time, considering the entire dormancy period as unity, and the value of $\mathrm{k}_{\mathrm{A} 1}$ was inferred to be equal to the slope of regression line (fig. 1). Data points indicated as open squares were excluded from analysis. These observations were considered to represent underestimates because they were obtained in winter months when the soil was frozen and bugs were hiding in concealed locations; higher numbers of bugs were observed on subsequent dates.

\section{Life tables and $k$-values}

The numbers of parental females observed at the various locations varied by more than an order of magnitude, as did the actual numbers of eggs observed (table 3 ). This variation was reduced by half in the $F_{2}$ generation due to the action of density-dependent mortality factors, the relative contributions of which are reported in table 4 .

\section{Analysis of key factors and density dependence}

(i) Analysis according to Podoler \& Rogers (1975) revealed that adult mortality $\left(\mathrm{k}_{\mathrm{A}}\right)$ was the key factor accounting for 38 to $76 \%$ of total mortality with a slope of 0.733 . Egg mortality $\left(\mathrm{k}_{\mathrm{E}}\right)$ was secondary with a slope of 0.63 , omitting $\mathrm{k}_{\mathrm{A}}$, and nymphal mortality $\left(\mathrm{k}_{\mathrm{N}}\right)$ was third in importance. Dividing stage mortalities into submortalities produced similar results, with $\mathrm{k}_{\mathrm{A} 1}$ and $\mathrm{k}_{\mathrm{A} 2}$ emerging as factors of first and secondary importance and accounting
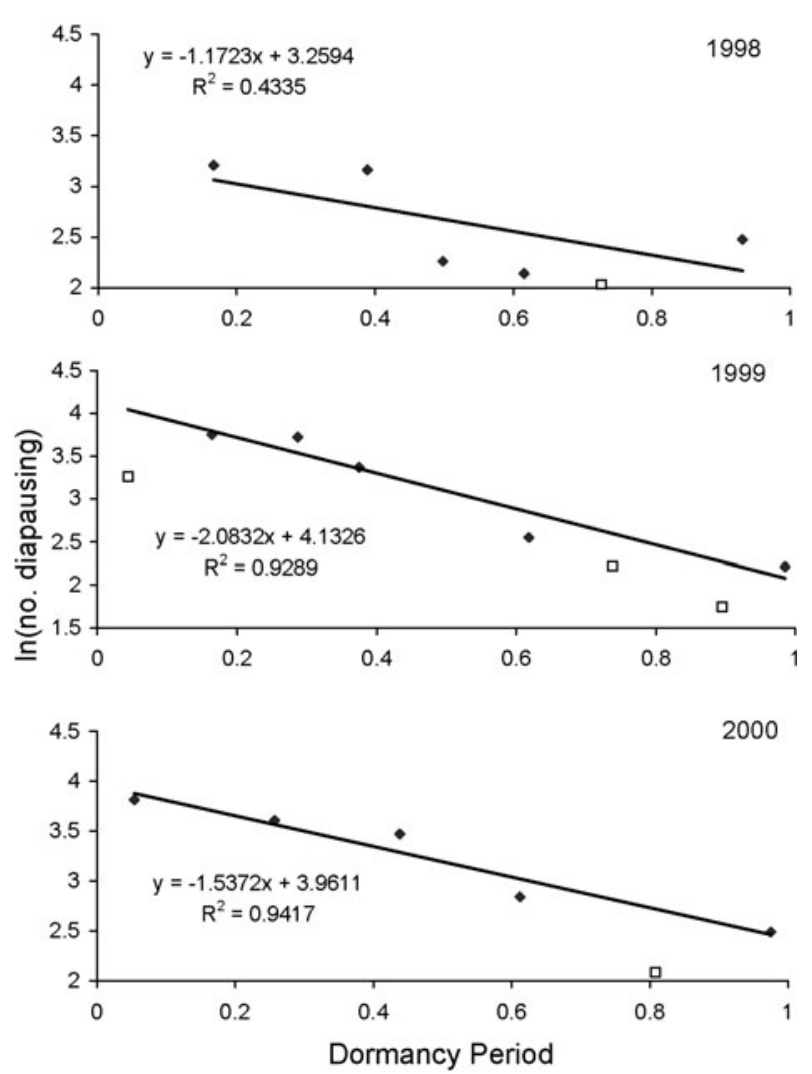

Fig. 1. Progressive adult mortality of Eurygaster integriceps in resting sites throughout the entire period of dormancy (unity) in three separate years expressed as a linear functions of the natural log of average numbers of bugs per plants sampled. Open symbols were construed to be underestimates based on subsequent data and were excluded from analysis.

for mortality ranging from $69-88 \%$ and $10-57 \%$ with slopes of 0.417 and 0.335 , respectively. Omitting $\mathrm{k}_{\mathrm{A} 1}$ enhanced the slope of $\mathrm{k}_{\mathrm{A} 2}$ to 0.497 . Subsequent factors were $\mathrm{k}_{\mathrm{E} 4}$ (T. vassilievi causing 0-60\% mortality), female parasitism by tachinids $\left(\mathrm{k}_{\mathrm{P} 1}\right)$ and total nymphal mortality $\left(\mathrm{k}_{\mathrm{N}}\right)$. 
Table 3. Numbers of Eurygaster integriceps (per $\mathrm{m}^{2}$ ) observed in successive life stages at various sites in northern Iran over three years. Potential egg numbers were inferred from numbers of parental females based on laboratory measurements of fecundity.

\begin{tabular}{|c|c|c|c|c|c|}
\hline \multirow[t]{2}{*}{ Life stage } & \multicolumn{3}{|c|}{ Jalilabad wheat } & \multirow{2}{*}{$\frac{\text { Jalilabad barley }}{1999}$} & \multirow{2}{*}{$\frac{\text { Sharifabad wheat }}{2000}$} \\
\hline & 1998 & 1999 & 2000 & & \\
\hline Parental females & 0.6 & 4.2 & 2.6 & 9.6 & 8.3 \\
\hline Observed eggs & 79.6 & 454.4 & 257.6 & 888.2 & 1318.1 \\
\hline 1st nymphal instar & 49.4 & 243.4 & 151.8 & 462.5 & 313.4 \\
\hline F2 adults & 26.7 & 94.2 & 49.1 & 194.5 & 149.3 \\
\hline Reproductive females & 4.2 & 2.6 & 3.8 & - & - \\
\hline
\end{tabular}

Reproductive females are the numbers of F2 females returning from dormancy sites.

(ii) Analysis according to Smith (1973) produced matrices of correlation and covariance between stage-specific $\mathrm{k}$-values and total mortality $(\mathrm{K})$ as follows:

\begin{tabular}{lrrrrrr}
\hline \multicolumn{7}{c}{ Correlation Matrix } \\
\hline \multicolumn{1}{c}{$\mathrm{k}_{\mathrm{P}}$} & $\mathrm{k}_{0}$ & \multicolumn{1}{c}{$\mathrm{k}_{\mathrm{E}}$} & $\mathrm{k}_{\mathrm{N}}$ & \multicolumn{1}{c}{$\mathrm{k}_{\mathrm{A}}$} & $\mathrm{K}$ \\
\hline $\mathrm{k}_{\mathrm{P}}$ & 1 & & & & & \\
$\mathrm{k}_{0}$ & -0.756 & 1 & & & & \\
$\mathrm{k}_{\mathrm{E}}$ & $0.950^{*}$ & -0.747 & 1 & & & \\
$\mathrm{k}_{\mathrm{N}}$ & -0.242 & 0.623 & -0.276 & 1 & & \\
$\mathrm{k}_{\mathrm{A}}$ & -0.568 & 0.721 & -0.346 & 0.439 & 1 & \\
$\mathrm{~K}$ & -0.092 & 0.503 & 0.105 & 0.567 & 0.853 & 1 \\
\hline
\end{tabular}

* significant at $95 \%$ level.

\begin{tabular}{lrrrrrr}
\hline \multicolumn{7}{c}{ Covariance Matrix } \\
\hline & \multicolumn{1}{c}{$\mathrm{k}_{\mathrm{P}}$} & \multicolumn{1}{c}{$\mathrm{k}_{0}$} & \multicolumn{1}{c}{$\mathrm{k}_{\mathrm{E}}$} & $\mathrm{k}_{\mathrm{N}}$ & $\mathrm{k}_{\mathrm{A}}$ & $\mathrm{K}$ \\
\hline $\mathrm{k}_{\mathrm{P}}$ & 0.041 & & & & & \\
$\mathrm{k}_{0}$ & -0.033 & 0.047 & & & & \\
$\mathrm{k}_{\mathrm{E}}$ & 0.075 & -0.064 & 0.155 & & & \\
$\mathrm{k}_{\mathrm{N}}$ & -0.010 & 0.026 & -0.021 & 0.038 & & \\
$\mathrm{k}_{\mathrm{A}}$ & -0.091 & 0.123 & -0.108 & 0.068 & 0.626 & \\
$\mathrm{~K}$ & -0.017 & 0.100 & 0.038 & 0.102 & 0.619 & 0.845 \\
\hline
\end{tabular}

The correlation matrix revealed that adult mortality $\left(\mathrm{k}_{\mathrm{A}}\right)$ had the strongest correlation with $\mathrm{K}$ and that mortality of all life stages except parental adults and eggs had an intermediate correlation with $\mathrm{K}$. The significant correlation between egg and parental mortality reflects the density-dependent nature of mortality factors affecting both, just as the negative correlation of $\mathrm{k}_{\mathrm{A}}$ with adult parasitism $\left(\mathrm{k}_{\mathrm{P}}\right)$ and egg mortality $\left(k_{E}\right)$ reflects overcompensatory density-dependent mortality across successive life stages. Out of total mortality, the covariance matrix assigned $73.3 \%$ of the variance $(0.619$ / 0.845 ) to adult mortality, $12 \%$ to both nymphal mortality and the difference between potential and realized fecundity, and only $4.5 \%$ to egg mortality. Dividing stage-specific mortalities into submortalities (not shown) had similar results; $\mathrm{k}_{\mathrm{A} 1}$ was the primary factor, contributing $60.7 \%$ of the variance in $\mathrm{K}$, followed by $\mathrm{k}_{\mathrm{A} 2}$ with $33.5 \%$, with high correlation between the two $(\mathrm{r}=0.95)$. Loss of fecundity $\left(\mathrm{k}_{0}\right)$ and egg parasitism by T. vassilievi $\left(\mathrm{k}_{\mathrm{E} 4}\right)$ accounted for $12.5 \%$ and $9.9 \%$ of variance in total mortality, respectively.

Manly's (1977, 1979) analysis differs from the other methods in that variation in stage-specific mortalities are compared to variation in density of the final life stage rather than total mortality $(\mathrm{K})$, so all sources of mortality are considered to be a series of density-dependent factors responsible for some proportion of the variance in final density. Therefore, the analysis begins by determining relationships between successive life stages, as follows:

$$
\begin{array}{ll}
\text { Parental adults: } & \mathrm{k}_{\mathrm{P}}=0.0976 * \mathrm{R}_{\mathrm{P}}+0.5270 ;\left(\mathrm{r}^{2}=0.34\right) \\
\text { Potential eggs: } & \mathrm{k}_{0}=0.0185 * \mathrm{R}_{0}+0.4733 ;\left(\mathrm{r}^{2}=0.01\right) \\
\text { Actual eggs: } & \mathrm{k}_{\mathrm{E}}=0.2592 * \mathrm{R}_{\mathrm{E}}-0.8122 ;\left(\mathrm{r}^{2}=0.53\right) \\
\text { Nymphs: } & \mathrm{k}_{\mathrm{N}}=0.0804 * \mathrm{R}_{\mathrm{N}}+0.4371 ;\left(\mathrm{r}^{2}=0.12\right) \\
\text { Adults: } & \mathrm{k}_{\mathrm{A}}=1.3044 * \mathrm{R}_{\mathrm{A}}-3.1265 ;\left(\mathrm{r}^{2}=0.94\right)
\end{array}
$$

Thus, there exist three density-dependent stage-specific mortalities. Parental mortality was only weakly densitydependent (slope $<0.1$ ) and had a moderate correlation with final density $(r=0.58)$. Egg mortality was intermediate in terms of density-dependence (slope $<1$ ) and had a stronger correlation $(\mathrm{r}=0.73)$, whereas adult overcompensatory mortality was strongly density-dependent (slope $>1$ ) and strongly correlated with final density $(r=0.97)$. Nymph mortality exhibited poor density dependence $(r=0.35)$.

Among submortalities, there were some density-dependent factors. Parasitism by tachinids demonstrated an intermediate correlation with female density $(r=0.59$, $b=0.123$ ), indicating that flies respond only weakly to increasing densities of parental bugs. Among Trissolcus species, only $T$. vassilievi showed a density-dependent response to its host $(r=0.85, b=0.264)$, whereas $T$. grandis responded in a density-independent manner $(r=0.17$, $b=0.008$ ). In contrast to their response to parental bugs, tachinids demonstrated a weak inverse density-dependent response to newly molted adults $(\mathrm{r}=-0.73)$, although their effect was generally weak (max. $=15 \%$ in 1998). Finally, although both $\mathrm{k}_{\mathrm{A} 1}$ and $\mathrm{k}_{\mathrm{A} 2}$ were density-dependent, their relative contributions could not be partitioned using this analysis because the latter is inclusive of the former. However, we were able to explore the relationship between $\mathrm{k}_{\mathrm{A} 1}$ and the density of adults returning to fields after the dormancy period. The numbers of adults on Artemisia plants in the mountains at the beginning of the dormancy period were highly correlated to density of adults in the cultivated fields prior to migration and those at the end of the dormancy period to the densities of adults returning to fields the following year ( $\mathrm{r}=0.90$ and 0.84 , respectively). These calculations were only possible for the three sets of data from Jalilabad wheat fields. The following relationships 
Table 4. Estimated contributions of various factors to Eurygaster integriceps mortality (k-values) over three years at three locations in northern Iran (see text for calculations).

\begin{tabular}{|c|c|c|c|c|c|c|c|}
\hline \multirow[t]{2}{*}{ Life stage } & \multirow[t]{2}{*}{$d_{x} F$} & & \multicolumn{3}{|c|}{ Jalilabad wheat } & \multirow{2}{*}{$\frac{\text { Jalilabad barley }}{1999}$} & \multirow{2}{*}{$\frac{\text { Sharifabad wheat }}{2000}$} \\
\hline & & & 1998 & 1999 & 2000 & & \\
\hline Parental females & $\begin{array}{l}\text { Sex ratio } \\
\text { Female parasitism }\end{array}$ & $\begin{array}{l}\mathrm{k}_{\mathrm{P}} \\
\mathrm{k}_{\mathrm{P} 1} \\
\mathrm{k}_{\mathrm{P} 2}\end{array}$ & $\begin{array}{l}0.6122 \\
0.3483 \\
0.264\end{array}$ & $\begin{array}{l}0.5669 \\
0.2736 \\
0.2933\end{array}$ & $\begin{array}{l}0.6904 \\
0.2433 \\
0.4471\end{array}$ & $\begin{array}{l}0.6561 \\
0.374 \\
0.2821\end{array}$ & $\begin{array}{l}1.0732 \\
0.2024 \\
0.8708\end{array}$ \\
\hline $\begin{array}{l}\text { Expected eggs } \\
\text { Actual eggs }\end{array}$ & $\begin{array}{l}\text { Predation } \\
\text { O. telenomicida } \\
\text { T. grandis } \\
\text { T. vassilievi } \\
\text { T. semistriatus } \\
\text { T. basalis } \\
\text { Infertility }\end{array}$ & $\begin{array}{l}\mathrm{k}_{0} \\
\mathrm{k}_{\mathrm{E}} \\
\mathrm{k}_{\mathrm{E} 1} \\
\mathrm{k}_{\mathrm{E} 2} \\
\mathrm{k}_{\mathrm{E} 3} \\
\mathrm{k}_{\mathrm{E} 4} \\
\mathrm{k}_{\mathrm{E} 5} \\
\mathrm{k}_{\mathrm{E} 6} \\
\mathrm{k}_{\mathrm{E} 7}\end{array}$ & $\begin{array}{l}0.4961 \\
0.477 \\
0.0206 \\
0.0 \\
0.3186 \\
0.0 \\
0.0 \\
0.0 \\
0.1379\end{array}$ & $\begin{array}{l}0.6607 \\
0.6242 \\
0.0166 \\
0.0131 \\
0.2634 \\
0.2321 \\
0.0204 \\
0.0 \\
0.1\end{array}$ & $\begin{array}{l}0.7292 \\
0.529 \\
0.0072 \\
0.0 \\
0.2165 \\
0.1744 \\
0.0 \\
0.0218 \\
0.1231\end{array}$ & $\begin{array}{l}0.8198 \\
0.6526 \\
0.0094 \\
0.0034 \\
0.2758 \\
0.3459 \\
0.0125 \\
0.0055 \\
0.0458\end{array}$ & $\begin{array}{l}0.2725 \\
1.4363 \\
0.0007 \\
0.0079 \\
0.3452 \\
0.9076 \\
0.0 \\
0.0 \\
0.1747\end{array}$ \\
\hline $\begin{array}{l}\text { 1st nymphal instar } \\
\text { F2 adults }\end{array}$ & $\begin{array}{l}\text { Diapause } \\
\text { Residual }\end{array}$ & $\begin{array}{l}\mathrm{k}_{\mathrm{N}} \\
\mathrm{k}_{\mathrm{A}} \\
\mathrm{k}_{\mathrm{A} 1} \\
\mathrm{k}_{\mathrm{A} 2}\end{array}$ & $\begin{array}{l}0.6146 \\
1.2826 \\
1.1723 \\
0.1104\end{array}$ & $\begin{array}{l}0.949 \\
2.9186 \\
2.0832 \\
0.8356\end{array}$ & $\begin{array}{l}1.1282 \\
1.7138 \\
1.5372 \\
0.1765\end{array}$ & $\begin{array}{l}0.8663 \\
2.7264 \\
2.0832 \\
0.6432\end{array}$ & $\begin{array}{r}0.7416 \\
1.2673 \\
1.5372 \\
-0.2699\end{array}$ \\
\hline
\end{tabular}

were obtained between $\mathrm{k}_{\mathrm{A} 1}$ and the natural log of density:

$$
\begin{aligned}
& \mathrm{k}_{\mathrm{A} 1}=0.8917 \times \mathrm{R}_{\mathrm{A}}^{\prime}-1.777\left(\mathrm{r}^{2}=0.81\right) \\
& \mathrm{k}_{\mathrm{A} 1}=0.7244 \times \mathrm{R}_{\mathrm{A}}-1.2336\left(\mathrm{r}^{2}=0.99\right)
\end{aligned}
$$

in which $R_{A}^{\prime}$ and $R_{A}$ were natural logarithms of adult densities per Artemisia plant and per $\mathrm{m}^{2}$ of wheat field, respectively. Thus, the survival of adults was more strongly dependent on adult density in cultivated fields, where they compete with one another for food, than on density at resting sites, where they are largely inactive.

Manly's key factor analysis was performed for whole life stages and again for submortalities, once according to the natural sequence of stages, and again in a sequence terminating in newly molted adults, the most injurious stage. When whole stages were considered in their natural sequence, $\mathrm{k}_{\mathrm{A}}$ was the key factor and removal of $\mathrm{k}_{\mathrm{A}}$ led to a 2.19-fold increase in the variance of the final stage. Parental adult and egg mortalities were of next most importance, contributing $20 \%$ and $2.5 \%$ of the variance, respectively. All remaining stage-specific mortalities had an impact of $<0.5 \%$ on variance in the number of ovipositing females.

When submortalities were included in the natural sequence analysis, variance of the final stage was 1.426 , and the largest deviations occurred when either $\mathrm{k}_{\mathrm{A}}$ or $\mathrm{k}_{\mathrm{P} 2}$ were eliminated (a 26.1\% decrease and $24.5 \%$ increase, respectively). Subsequent factors were Trissolcus spp. and $\mathrm{k}_{\mathrm{P} 1}$, that caused a $6.3 \%$ increase and $4.3 \%$ decrease in variance, respectively, when removed. Replacing Trissolcus spp. with either T. grandis or T. vassilievi had negligible effects.

When the stage sequence was arranged so that newly molted adults were the final stage, variance of this stage was estimated to be 0.77, with Trissolcus spp. and female parasitism by tachinids key factors contributing variance increase of $77 \%$ and $22 \%$, respectively, when eliminated. A 2.2-fold increase in variance was observed when both factors were eliminated simultaneously. Removal of adult mortality, $\mathrm{k}_{\mathrm{A}}$, had a minor effect on variance in numbers of newly molted adults, causing a $13.2 \%$ decrease. Substitution of T. grandis for Trissolcus spp. increased variance to 1.34, but its further elimination had a negligible effect. On the other hand, this substitution enhanced the contribution of $\mathrm{k}_{\mathrm{A}}$ and rendered it the key factor contributing to a $92 \%$ increase in variance, apparently due to the replacement of a density-dependent mortality factor with a densityindependent one.

Meteorological data: Adult mortality $\left(\mathrm{k}_{\mathrm{A}}\right)$ emerged as the major key factor in all analyses. Dormancy begins with period of aestivation and meteorological data revealed negligible variation among years in average summer temperatures (29.4-29.8 ${ }^{\circ} \mathrm{C}$ from late June to late September). However, this is a dry period, in which not more than $14 \mathrm{~mm}$ of rainfall was recorded in any year. Seasonal rainfall occurred in different months of autumn in the various years. In 1998, rainfall did not occur prior to late November, resulting in a relatively warm, dry autumn, including five months of drought with an average temperature of $17.2^{\circ} \mathrm{C}$ from late September to late December. The mean temperature from late December to late March (winter) in 1998 was $8.5^{\circ} \mathrm{C}$, with a minimum of $-5.5^{\circ} \mathrm{C}$ recorded in early January. The year 1999 was characterized by an abrupt onset of cold weather, with the average temperature dropping $10^{\circ} \mathrm{C}$ in the last week of October, followed by persistent rainy weather that prevented any restoration of warmer temperatures. The minimum winter temperature was $-7.0^{\circ} \mathrm{C}$ recorded mid-January. However, the bulk of mortality occurred in early October, before the seasonal rains. In 2000, seasonal rainfall began in early October and autumn was more cold and damp in comparison with previous years. The average autumn temperature was $13.6^{\circ} \mathrm{C}$, as opposed to 17.2 and $14.5^{\circ} \mathrm{C}$ for the same period during 1998 and 1999, respectively. The average temperature during winter months was $8.0^{\circ} \mathrm{C}$, with a minimum of $-6.5^{\circ} \mathrm{C}$ recorded in late January, and the temperature decline through autumn was gradual, allowing ample opportunity for the bugs to acclimate. 


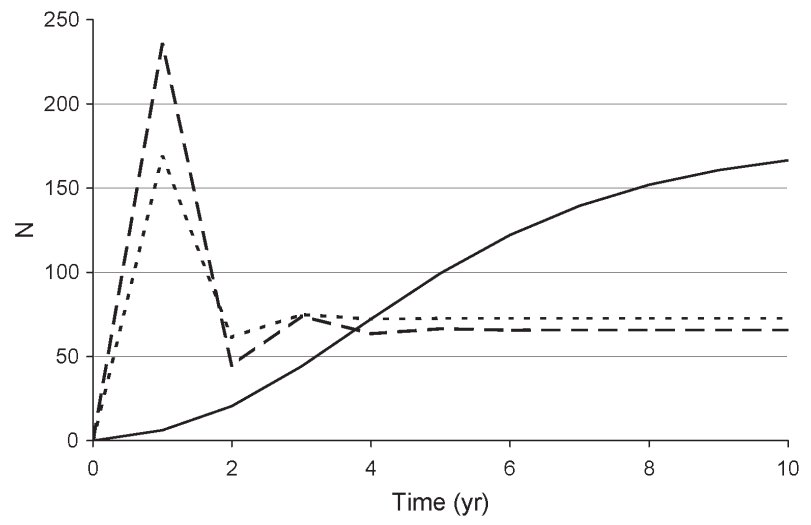

Fig. 2. Annual changes in numbers of E. integriceps newly molted adults across two generations inferred from three deterministic models. Model 1 simulates fluctuations arising when all mortality factors are density-dependent (adult mortality, female parasitism by tachinid flies, and egg parasitism; equation 13) with constant $\mathrm{k}$-values inserted for remaining factors. Model 2 is the same except that parasitism is assumed to be density-independent (equation 14) and model 3 assumes density-independent adult mortality with density-dependent natural enemies (equation 15) (--- model 1 ; -- model 2 ; model 3).

\section{Population regulation model}

A population model was constructed considering only the three major density-dependent sources of mortality: immature adult mortality $\left(\mathrm{k}_{\mathrm{A}}\right)$, female parasitism by tachinids $\left(\mathrm{k}_{\mathrm{P} 2}\right)$ and egg parasitism by $T$. vassilievi $\left(\mathrm{k}_{\mathrm{E} 4}\right)$ represented as follows:

$$
\begin{gathered}
\mathrm{k}_{\mathrm{A}}=1.3044 \times \mathrm{R}_{\mathrm{A}}-3.1265 \\
\mathrm{k}_{\mathrm{P} 2}=0.1226 \times \mathrm{R}_{+}+0.2246 \\
\mathrm{k}_{\mathrm{E} 4}=0.2644 \times\left[\mathrm{R}_{\mathrm{E}}-\mathrm{k}_{\mathrm{E} 1}-\mathrm{k}_{\mathrm{E} 2}\right]-1.2516
\end{gathered}
$$

in which $R_{i}$ is the natural $\log$ of the number of stage $i$. The number of each stage is calculated by subtracting the respective $k$-value from the $\ln$ number of the previous stage. Thus, parental density in a given year can be described as a function of the number of immature adults in the previous year as follows:

$$
R_{P}=-0.3044 \times R_{A}+3.1265
$$

Starting with the parental generation, subtracting sequential $\mathrm{k}$-values up to immature adults in the following generation, considering the factors $\mathrm{k}_{\mathrm{P} 2}$ and $\mathrm{k}_{\mathrm{E} 4}$ (obtained from equations 10 and 11), assuming a constant potential fecundity of 209.36 and adding unity in order to avoid any logarithm of zero, yields:

$$
\ln \mathrm{N}_{\mathrm{A}(\mathrm{t}+1)}=-0.1965 \times \ln \left(\mathrm{N}_{\mathrm{A}(\mathrm{t})}+1\right)+5.1272
$$

in which $\mathrm{N}_{\mathrm{A}}$ is the number of immature adults in generations $t$ and $t+1$.

Taking the limit of equation 13 yields 168.54, the maximum possible yearly increase in population density, such as might occur if a density-independent event reduced the population to nearly zero. Solving for equilibrium $(\lambda=1)$, such that $\ln \mathrm{N}_{\mathrm{A}(\mathrm{t}+1)}=\ln \mathrm{N}_{\mathrm{A}(\mathrm{t})}$ in equation 13 , yields an equilibrium density of $72.62 \mathrm{~F} 2$ bugs m $^{-2}$ (fig. 2, model 1). This is somewhat less than 102.77, the observed average of

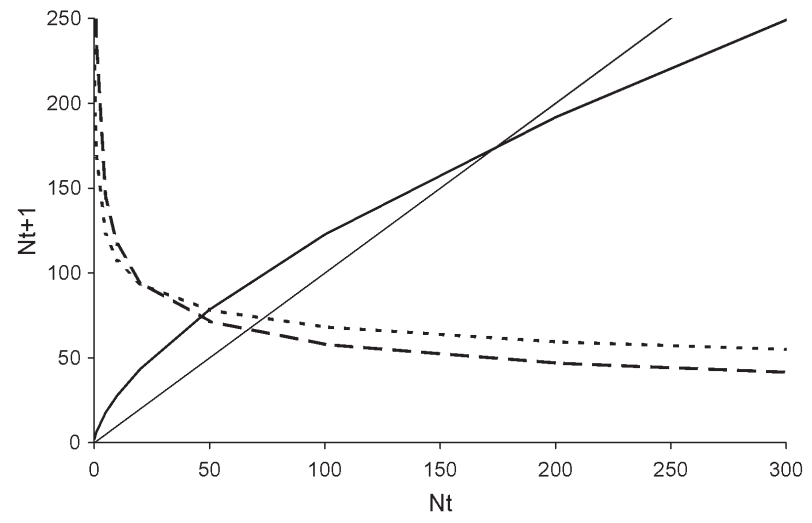

Fig. 3. Population replacement curves of E. integriceps inferred from three deterministic models (equations 13, 14 and 15, respectively) assuming different initial densities (-- - model 1; - - model 2; — model 3; —— net replacement).

the five fields sampled. Starting at zero, equilibrium is obtained after four iterations of the model. If different values of $\mathrm{N}_{\mathrm{t}}$, ranging from 0 to 168.54 , are plotted against $\mathrm{N}_{\mathrm{t}+1}$, a negative exponential curve is obtained that approaches an asymptotic minimum at 61.55 (fig. 3, model 1).

In order to explore the regulatory role of densitydependent factors, we replaced k-values for natural enemies $\left(\mathrm{k}_{\mathrm{P} 2}\right.$ and $\left.\mathrm{k}_{\mathrm{E} 4}\right)$ with a constant of similar average and obtained equation 14 that yielded a lower equilibrium population of $65.81 \mathrm{~m}^{-2}$ and a wider range of fluctuations (model 2 in figs 2 and 3).

$$
\ln \mathrm{N}_{\mathrm{A}(\mathrm{t}+1)}=-0.3044 \times \ln \mathrm{N}_{\mathrm{A}(\mathrm{t})}+5.4612
$$

This illustrates how natural enemies stabilize population fluctuations; when a key mortality factor has been overcompensatory, subsequent mortality is reduced. On the other hand, replacing a constant $\mathrm{k}$-value of 1.9717 in place of equation 9 yields equation 15 :

$$
\ln \mathrm{N}_{\mathrm{A}(\mathrm{t}+1)}=0.6454 \times \ln \mathrm{N}_{\mathrm{A}(\mathrm{t})}+1.8368
$$

This results in a 2.5-fold increase in the equilibrium level to 177.65 (model 3 in figs 2 and 3). Thus, we conclude that $\mathrm{k}_{\mathrm{A}}$ is a key factor regulating the population at a lower equilibrium density than would otherwise occur.

Equations 13, 14 and 15 are deterministic models of population dynamics that converge to constant values and do not account for any environmental stochasticity. The addition of experimental errors $(\varepsilon)$ of all k-values as random, normally-distributed statistics to the above equations results in stochastic models that fluctuate continuously. Note that $\varepsilon$ is not a simple summation of the $\varepsilon_{\mathrm{ij}}$ 's of $\mathrm{k}$-values because, in the case of density-dependent factors, $\varepsilon_{\mathrm{ij}}$ 's vary along the regression line. We performed 30 simulations for each stochastic model by randomly selecting sequential k-values from normal distributions with averages and variances similar to the observed data (table 5, fig. 4).

It is evident that replacement of a density-dependent factor with a density-independent one of similar average tends to increase the variance and mean number of adults. Variation also scaled with the strength of density dependence. Thus, the range of population variation is more limited in model 1 than in models 2 and 3 because 
Table 5. Summary of results for numbers of Eurygaster integriceps adults after 30 iterations of three different stochastic models over 15 generations (see text for model details).

\begin{tabular}{lrrr}
\hline Parameters & Model 1 & Model 2 & Model 3 \\
\hline Minimum & 27.82 & 14.12 & 10.61 \\
Mean & 76.59 & 79.79 & 199.44 \\
Maximum & 199.99 & 398.08 & 1875.42 \\
Variance & 554.09 & 2007.08 & 37139.95 \\
Standard deviation & 23.54 & 44.80 & 192.72 \\
CV (\%) & 30.74 & 56.15 & 96.63 \\
\hline
\end{tabular}

density-dependent factors serve to regulate population fluctuations within a narrower range of values (fig. 4).

\section{Discussion}

An equilibrium population density estimate of 72.6 adults $\mathrm{m}^{-2}$ is in accordance with the results of Amir Maafi (2000), who obtained an estimate of 81 adults $\mathrm{m}^{-2}$ in the same region. The three methods used for key factor analysis of sunn pest mortality all produced results in general agreement with one another and identified adult mortality $\left(\mathrm{k}_{\mathrm{A}}\right)$ as the primary factor, generating the steepest slope of all regression lines that related $\mathrm{k}$-values to total mortality, $\mathrm{K}$ (0.733). This mortality had an overcompensatory densitydependent effect with a slope of 1.3 of $\mathrm{k}_{\mathrm{A}}$ on the natural $\log$ of adult density in the field. The rate of mortality depends on population density during the pre-reproductive feeding period. Sources of mortality include starvation due to inadequate fat reserves, parasitism and predation, and abiotic factors associated with severe weather conditions (Banita et al., 1994; Critchley, 1998; Radjabi, 2007). Our results are in general agreement with the findings of Radjabi $(2000,2007)$ in Isfahan, central Iran, who divided total E. integriceps mortality into five stage mortalities including egg, nymph 1, nymph 2, nymphs 3 to 5 together, and newly molted adult. Adult mortality emerged as the key factor with a slope of 0.931 , very near to the value obtained in this study.

Overcompensatory mortality may diminish population density to a level lower than that required to maintain a population in a steady state. Adult mortality explained almost three quarters of total mortality, and its elimination had the largest effect of any k-value on variance in numbers of the final life stage, i.e. ovipositing females, resulting in a $26 \%$ decrease when it was eliminated from natural sequence of mortality fractions. This factor embodied mortality incurred during four ecologically distinct periods: premigratory feeding, migration to resting sites, dormancy and the return migration to wheat fields for reproduction. There was also general agreement in results whether analyses were performed using mortalities for whole life stages or by submortalities. Adult mortality during the dormancy period, $\mathrm{k}_{\mathrm{A} 1}$, was the most important fraction, followed by residual adult mortality, $\mathrm{k}_{\mathrm{A} 2}$. Thus, in terms of reducing the numbers of reproductive females arriving in wheat fields in spring, mortality during the dormancy period was more important than mortality occurring during premigratory feeding and both migrations combined.

Prior to the widespread use of insecticides against E. integriceps in Isfahan, an outbreak occurred every 5-8
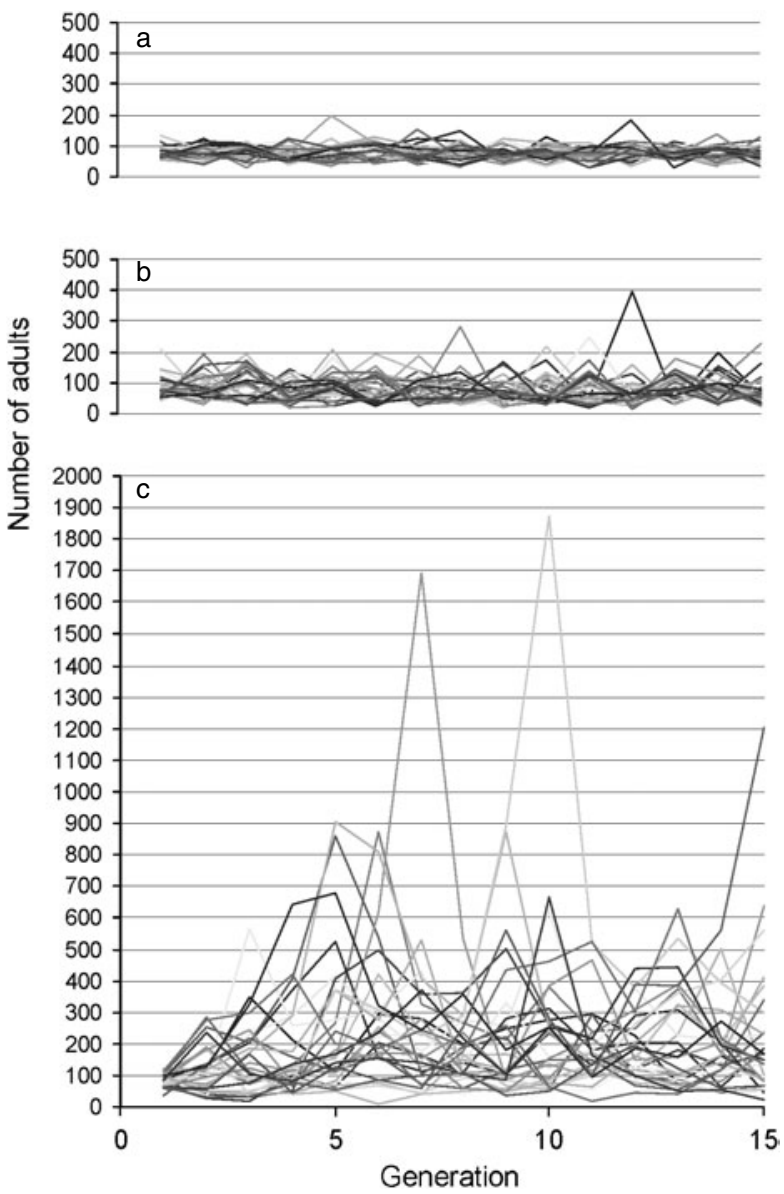

Fig. 4. Fluctuations in numbers of E. integriceps adults inferred from stochastic iterations of models 1,2 and 3, respectively ((a) equation 13, (b) equation 14 and (c) equation 15) that incorporate normal errors $\left(\varepsilon_{\mathrm{ij}}\right)$ for different k-values over 30 simulations of 15 generations each.

years (seven years on average), with populations remaining elevated up to a year after each outbreak, whereas outbreaks in Varamin are capricious, alternating between high and low levels from one year to the next. Another possible difference between our study site and that of Radjabi (2007) is the rate of insecticide use. Pesticide applications reduce populations and thus the level of competition among surviving individuals, resulting in a smaller, but more vigorous, cohort entering diapause. This point has been emphasized in efforts to predict outbreaks of the pest based on its physiological state (Safavi, 1973; Doroninia \& Makarova, 1976; Salavatian, 1991; Udovitsa, 1998). Competition for food reduces the fat reserves that can be accumulated by bugs prior to dormancy, reserves that are essential to adult survival during diapause and that are gradually depleted during the resting period. Radjabi (1995b) showed that the average weight of bugs declines from 135-145 mg at the onset of aestivation to 100$110 \mathrm{mg}$ at the end of diapause and that lighter bugs suffer greater mortality. Consequently, the $5.5 \mathrm{mg}$ increase in body weight of diapausing bugs between December and January reported by Iranipour (2008) is likely due to disproportionate mortality among lighter bugs. 
Because of the intensity of their feeding, adults compete strongly among one another. The higher slope of adult mortality as opposed to nymphal mortality on total K, both in our study and that of Radjabi (2007), appears to support this inference. The fresh weight of adult E. integriceps ranges from $<100 \mathrm{mg}$ to $140 \mathrm{mg}$ (Safavi, 1973). Some authors have distinguished two size categories based on average body weight (i.e. means of $110 \mathrm{mg}$ and $130 \mathrm{mg}$ : Radjabi, 2000) or weight ranges (<115 and >125 mg: Salavatian, 1991). Radjabi (2000) reported that bugs of lower body size developed more slowly and laid only 50 to $70 \%$ as many eggs as heavier bugs. Overwintered bugs fed on wheat kernels had three times the fecundity of those fed on green wheat leaves (Iranipour, in press; Iranipour et al., in press), which are similar to the results obtained by Zomorrodi (1961). These results underscore the importance of food quality and availability to sunn pest population dynamics.

In contrast to the studies of Radjabi (2000, 2007), egg parasitism was a significant source of mortality in our study, likely due to the presence of $T$. vassilievi that is absent in Isfahan. Elimination of $T$. vassilievi from the sequence of mortality factors caused the greatest increase in variation in numbers of newly emerged adults. Some previous studies have attributed a key role to natural enemies, particularly parasitoids, in suppressing sunn pest populations (Banita et al., 1994; Kartavtsev, 1974; Gordeev, 1998; Udovitsa, 1998; Amir-Maafi \& Parker, 2002; Amir-Maafi et al., 2002). Interestingly, Banita et al. (1994), working in Romania, reported that starvation and fungal diseases killed between $3 \%$ and $81 \%$ of adults during hibernation in various years, suggesting that adult mortality is also an important regulatory factor in that country.

Both hymenopterous and dipterous parasitoids exhibited poor density dependence in our study. Although no records exist for the specific region of the study, more than ten species of tachinid fly have been reported from E. integriceps in Iran (Radjabi, 2000) and four species from Karaj, the records closest to Varamin: Ectophasia crassipennis (F.), Elomyia lateralis (Meigen), Heliozetha helluo L. and Phasia subcoleopterata L. (Amir-Maafi, 1991). Amir Maafi (1991), Ebadi \& Jozeyan (2000) and Jozeyan \& Ebadi (2000) obtained results similar to ours for $H$. helluo, $P$. subcoleopterata and $P$. crassipennis. However, inverse density-dependent parasitism by these flies has not been previously reported. Although T. grandis is recognized as the most important and widely distributed natural enemy of sunn pest in Iran (Radjabi \& Amir Nazari, 1989), it acted in a densityindependent manner in the present study and, therefore, did not place among the first ten factors affecting population dynamics of the pest. However, it tends to be the most abundant parasitoid at low pest densities (e.g. Amir-Maafi \& Parker, 2003).

Other studies have implicated weather conditions in sunn pest population dynamics in Iran (Heydari, 1986; Salavatian, 1991; Modarres Avval, 1992) and in other countries (Kartavtsev, 1974; Doroninia \& Makarova, 1976; Volodichev, 1991, 1996; Tikhomolov \& Borisov, 1998). It is often stated that the different thermal requirements of wheat and sunn pest can lead to asynchronies between the pest and its host plant in cold springs. However, our results did not suggest that climate was a key factor influencing population variation in the years of our study. Despite popular belief that higher mortality at resting sites occurs under warm, dry conditions, total mortality during the dry period of dormancy in 1998 was lower than in subsequent years that experienced cooler, damper conditions. Obviously, severe weather conditions are expected to interact with the physiological condition of diapausing bugs to substantially affect average rates of overwintering mortality. However, weather conditions over the course of the study were not sufficiently variable among years to contribute significant variation in the key factor analysis, whereas the physiological condition of diapausing bugs was.

It may be concluded that in dry, temperate zones, such as northern Iran, equilibrium populations of E. integriceps are well above the economic injury level for cereals and that natural forces are unable to reduce them to tolerable levels. Thus, populations increase until intraspecific competition among adults becomes the primary regulatory factor. The discrepancies between this and previous studies are most likely explained by the fact that weather conditions and natural enemies may have greater impact on population fluctuations in other regions, especially in marginal habitats along the periphery of the pest's range, even though damaging populations still occur in some years.

\section{Acknowledgements}

We are grateful to the farmers of Varamin County who let us to carry out our study in their fields and Mr Kurosh Rezapour of the Agriculture Office of Jalilabad Barrack. The authors also thank the Mamazan Weather Station of the Higher Education Institute of Aboureyhan, Faculty of Agriculture, University of Tehran. Others who assisted us in matters practical or official include Nazari, Nochehdeh Sadat, Ataei, Teymouri, Hosseyni, Matin, Ghasemi, Arab Alikhani, Hadj Mavla, Jalili Moghadam, Ahrari Moghadam, Sadaghati, Mir Abbasi and Radjabi Soltanabadi. This study was supported by the College of Agriculture, University of Tehran.

\section{References}

Afshar, J. (1933) Development, Life Cycle and Ecology of Sunn-Pest Eurygaster integriceps Put. in Iran. Tehran, Iran, Ferdowsi Publishers.

Alexandrev, N. (1947a) Eurygaster integriceps Put. a Varamine et ses parasites. Entomologie et Phytopathologie Appliquees 5, 11-14.

Alexandrev, N. (1947b) Eurygaster integriceps Put. a Varamine et ses parasites. Entomologie et Phytopathologie Appliquees $\mathbf{6}$ and 7, 8-17.

Amir-Maafi, M. (1991) An investigation for identifying the efficiency of parasitoid flies of cereal sunn pest (Eurygaster integriceps Put.) in Karaj, Iran. MSc thesis, University of Tehran, Iran.

Amir-Maafi, M. (2000) An investigation on the host-parasitoid system between Trissolcus grandis Thomson (Hym.: Scelionidae) and sunn pest eggs. PhD thesis, University of Tehran, Iran.

Amir-Maafi, M. \& Parker, B.L. (2002) Density dependence of Trissolcus spp. (Hymenoptera: Scelionidae) on eggs of Eurygaster integriceps Puton (Hemiptera: Scutelleridae). Arab Journal of Plant Protection 20, 62-64. 
Amir-Maafi, M. \& Parker, B.L. (2003) Efficiency of Trissolcus spp. (Hymenoptera: Scelionidae) as egg parasitoids of Eurygaster integriceps Puton (Hemiptera: Scutelleridae) in Iran. Arab Journal of Plant Protection 21, 69-72.

Amir-Maafi, M., Kharrazi Pakdel, A., Sahragard, A. \& Rasoulian, G. (2002) Efficiency and regulation mechanisms of sunn pest population, Eurygaster integriceps Put. (Het. Scutelleridae), by egg parasitoids in Varamin. Journal of Entomological Society of Iran 22, 29-47.

Banita, E., Popov, C. \& Luca, E. (1994) Study of the main ecological factors controlling the population of Eurygaster integriceps Put. in the central zone of Oltenia. Probleme de Protectia Plantelor 22, 245-259.

Bellows Jr, T.S., van Driesch, R.G. \& Elkinton, J.S. (1992) Lifetable construction and analysis in the evaluation of natural enemies. Annual Review of Entomology 37, 587-614.

Bernal, J. \& Gonzalez, D. (1993) Experimental assessment of degree-day model for predicting the development of parasites in the field. Journal of Applied Entomology 116, 456-466.

Carey, J.R. (1993) Applied Demography for Biologists with Special Emphasis on Insects. Oxford, UK, Oxford University Press.

Critchley, B.R. (1998) Literature review of sunn pest, Eurygaster integriceps Put. (Hemiptera, Scutelleridae). Crop Protection 17, 271-287.

Davatchi, A. (1954) Insect Pests of Iran: Grasshoppers and Other Cereal Insect Pests. Tehran, Iran, University of Tehran Publication.

Dent, D.R. (1997) Quantifying insect populations: estimates and parameters. pp. 57-109 in Dent, D.R. \& Walton, M.P. (Eds) Methods in Ecological and Agricultural Entomology. Wallingford, UK, CAB International.

Doroninia, G.M. \& Makarova, L.A. (1976) Geographical characteristics of the population dynamics of a noxious pentatomid and their simulation by models. Trudy Vsesoyuznogo Nauchno issledovatel' skogo Instituta Zashchity Rastenii 50, 76-102.

Ebadi, R. \& Jozeyan, A. (2000) A study of the biology of parasitoid fly, Phasia subcoleopterata L. (Dipt., Tachinidae), of sunn pest in Isfahan. p. 7 in Proceeding of the 14th Iranian Plant Protection Congress, vol. 1, Pests. 5-8 September 2000, Isfahan University of Technology, Isfahan, Iran.

Elkinton, J.S., Buonaccorsi, J.P. \& Bellows Jr, T.S. (1992) Marginal attack rate, k-values and density dependence in the analysis of contemporaneous mortality factors. Researches on Population Ecology 34, 29-44.

Farid, A. (1984) Preliminary investigations on sunn pest (Eurygaster integriceps Put.) in Jiroft. Bulletin of Plant Protection Organization 30, 74-86.

Ghadiri, V. \& Heydari, M. (1989) Some preliminary studies on sunn pest (Eurygaster integriceps Put.) in Bakhtaran province. Applied Entomology and Phytopathology 56, 23-24.

Gordeev, A. (1998) The situation is under control. Zashchita $i$ Karantin Rastenii 2, 11.

Heydari, M. (1986) Investigation on the variation on population density of Eurygaster integriceps in highlands during summer and winter times. p. 26 in Proceeding of the 8th Iranian Plant Protection Congress, 30 August-4 September 1986, Isfahan, Iran.

Iranipour, S. (2008) Relationship between fecundity, weight and body dimensions in Eurygaster integriceps Puton (Hem., Scutelleridae). p. 454 in Proceedings of the 18th Iranian Plant Protection Congress, vol. 1, Pests. 24-27 August 2008, University of Bu Ali Sina, Hamadan, Iran.
Iranipour, S. Effect of temperature on fecundity and longevity of adults of sunn-pest Eurygaster integriceps Put. (Het. Scutelleridae). Agricultural Research, Water, Soil \& Plant in Agriculture, in press.

Iranipour, S., Kharrazi Pakdel, A., Radjabi, G., Rasoulian, G. \& Karim Modjeni, H. (2003) Age specific mortality and temperature-dependent development of immature stages of sunn pest (Eurygaster integriceps Put.) (Heteroptera: Scutelleridae) in four constant temperatures. Applied Entomology and Phytopathology 70, 1-6.

Iranipour, S., Kharrazi Pakdel, A. \& Radjabi, G. Life history parameters of Eurygaster integriceps (Het., Scutelleridae) held at four constant temperatures. Journal of Insect Science, in press.

Javahery, M. (1978) Economical importance of sunn pests (Eurygaster and Aelia spp.) and their control in Iran. Plant Protection 27, 4-9.

Jozeyan, A. \& Ebadi, R. (2000) A study of efficiency of parasitoid flies of sunn pest Phasia sp. (Diptera,: Tachinidae) and effects of chemical control of sunn pest on its prevalent parasitoid species in Isfahan. p. 222 in Proceeding of the 14th Iranian Plant Protection Congress, vol. 1, Pests. 5-8 September 2000, Isfahan University of Technology, Isfahan, Iran.

Kartavtsev, N.I. (1974) Studying the role of naturally occurring Telenomines. Zashchita Rastenii 4, 31.

Khalaf, J. \& Shadai, M. (1990) Sunn pest (Eurygaster integriceps Put.) in Fars province. Applied Entomology and Phytopatho$\log y$ 57, 9-10.

Manly, B.F.J. (1977) The determination of key factors from life table data. Oecologia 31, 111-117.

Manly, B.F.J. (1979) A note on key factor analysis. Researches on Population Ecology 21, 30-39.

Manly, B.F.J. (1990) Stage-Structured Populations, Sampling, Analysis and Simulation. London, UK, Chapman and Hall.

Marashi, E. (1988) An investigation in sunn pest situation in Markazy province conditions. Bulletin of Plant Protection Organization 31, 91-111.

Mardoukhi, V. \& Heydari, M. (1993) Study on variations of population density and damage of sunn pest (Eurygaster integriceps Put.) in dry rain-fed area of Kurdestan. Applied Entomology and Phytopathology 60, 7-8.

Martin, H.E., Javahery, M. \& Radjabi, G. (1969) Note sur la Punaise des cereales Eurygaster integriceps Put. et de ses parasites du genre Asolcus en Iran. Entomologie et Phytopathologie Appliquees 28, 38-46.

Modarres Avval, M. (1992) Biology and ecology of sunn-pest (Eurygaster integriceps) and study on reasons of its outbreaks in Trakya region (European part of Turkey). pp. 51-70 in The 1st Technical Conference on Cereal Sunn Pest (Eurygaster integriceps Put.), 23-27 May 1992, College of Agriculture, University of Tehran, Karaj, Iran.

Morris, R.F. (1957) The interpretation of mortality data in studies of population dynamics. Canadian Entomologist 89, 49-69.

Morris, R.F. (1959) Single factor analysis in population dynamics. Ecology 40, 580-588.

Podoler, H. \& Rogers, D. (1975) A new method for the identification of key factors from life-table data. Journal of Animal Ecology 44, 85-115.

Radjabi, G. (1994) Analysis of sunn pest periodic outbreaks in Iran. Applied Entomology and Phytopathology 61, 1-10.

Radjabi, G. (1995a) Investigations on the various aspects of Hymenopterous egg parasitoids in alleviating the outbreak occurrence of Eurygaster integriceps in Iran. Applied Entomology and Phytopathology 62, 13-14. 
Radjabi, G. (1995b) Trend of body weight variations of Eurygaster integriceps Put.) in the fields and altitudes. Applied Entomology and Phytopathology 62, 15-16.

Radjabi, G. (2000) Ecology of Cereals' Sunn-Pests in Iran. Tehran, Iran, Ministry of Jihad and Agriculture, Agricultural Research, Education and Organization Publication.

Radjabi, G. (2007) Sunn Pest Management Based on Its Outbreaks' Key Factor Analysis in Iran. Tehran, Iran, Ministry of Jihad and Agriculture, Agricultural Research and Education Organization Publication.

Radjabi, G. \& Amir Nazari, M. (1989) Egg parasites of sunn pest in the central part of Iranian plateau. Applied Entomology and Phytopathology 56, 1-12.

Safavi, M. (1973) Etude Bio-Ecologique des Hymenopteres Parasites des Oeufs des Punaises des Cereales en Iran. Tehran, Iran, Institut de Researches Entomologiques et Phytopathologiques Publication.

Salavatian, M. (1991) The Necessity of Studying Ecological and Biological Effective Factors in Controlling Field Crop Pests. Tehran, Iran, Agricultural Extension Organization Publication.

Sibly, R.M. \& Smith, R.H. (1998) Identifying key factors using $\lambda$ contribution analysis. Journal of Animal Ecology 67, 17-24.

Slobodkin, L.B. (1962) Growth and Regulation of Animal Populations. New York, Holt Rinehart and Winston.

Southwood, T.R.E. \& Jepson, W.F. (1962) Studies on the populations of Oscinella frit L. (Dipt.: Chloropidae) in the oat crop. Journal of Animal Ecology 31, 481-495.
Southwood, T.R.E. \& Henderson, P.A. (2000) Ecological Methods. Blackwell Science, London, UK, Oxford.

Smith, R.H. (1973) The analysis of intra-generation change in animal populations. Journal of Animal Ecology 42, 611-622.

Tafaghodinia, B. (1994) Studies on population dynamics of cereal sunn pest Eurygaster integriceps Put. (Het., Scutelleridae) at Karaj. MSc thesis, University of Tehran, Karaj, Iran.

Tikhomolov, V.I. \& Borisov, S.Y. (1998) Factors regulating abundance of the sunn pest in the Saratov region. Zashchita i Karantin Rastenii 2, 10-11.

Udovitsa, M.I. (1998) The situation may change. Zashchita $i$ Karantin Rastenii 3, 15.

Varley, G.C. \& Gradwell, G.R. (1960) Key factors in population studies. Journal of Animal Ecology 29, 399-401.

Vojdani, S. (1961) Bio-ecology of some Eurygaster species in central California (Pentatomidae-Scutellerinae). Annals of the Entomological Society of America 54, 567-578.

Volodichev, M.A. (1991) The sunn pest. Zashchita-Rastenii 2, 9-12.

Volodichev, M.A. (1996) What about the Eurygaster bug? Zashchita i Karantin Rastenii 4, 10-11.

Yamamura, K. (1999) Key-factor/key-stage analysis for life table data. Ecology 80, 533-537.

Young, L.J. \& Young, J.H. (1998) Statistical Ecology. Norwell, MA, USA, Kluwer Academic Publishers.

Zomorrodi, A. (1961) A progress in biological control of sunnpest. Entomologie et Phytopathologie Appliquees 20, 16-23. 